\title{
Effect of Fluorocarbon Surfactant on Electroforming of Copper Nano-Powders
}

\author{
Zhongbao Luo, Yuchang Su*, Shixiang Yue, Qiushan Yu, Rabigul Tursun and Jing Zhang \\ School of Materials Science and Engineering, Central South University, Changsha 410083, China \\ *E-mail: ychsu@csu.edu.cn \\ doi: $10.20964 / 2021.02 .53$
}

Received: 13 November 2020 / Accepted: 8 December 2020 / Published: 31 December 2020

\begin{abstract}
The electrodeposition behavior, morphology, and particle size of copper nano-powders prepared using fluorocarbon surfactants or fluorocarbon combined with non-ionic compound surfactants were characterized by linear sweep voltammetry, cyclic voltammetry, X-ray diffraction, and field emission scanning electron microscopy. Copper nano-powders prepared using fluorocarbon surfactant or fluorocarbon, non-ionic compound surfactants without added sulfuric acid did not adhere to the plate. The fine particle size of the copper powders, which was mainly influenced by the anionic fluorocarbon surfactant, ranged from 50 to $200 \mathrm{~nm}$. The powder morphology mainly depended on the non-ionic surfactant, and the electrodeposition process was governed by diffusion. The cyclic voltammetry curve indicated that the cathode peak current density is inversely proportional to the plate surface coverage. The change of current density in the electrodeposition process was directly related to the current efficiency. The mechanism of the formation of copper nano-powders by microemulsion electrodeposition was established and explained.
\end{abstract}

Keywords: Fluorocarbon surfactant; copper nano-powders; linear sweep voltammetry; cyclic voltammetry

\section{FULL TEXT}

(C) 2021 The Authors. Published by ESG (www.electrochemsci.org). This article is an open access article distributed under the terms and conditions of the Creative Commons Attribution license (http://creativecommons.org/licenses/by/4.0/). 